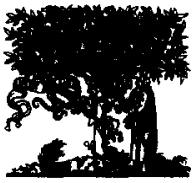

ELSEVIER

\title{
Genome plasticity in Neisseria gonorrhoeae
}

\author{
Carol P. Gibbs *, Thomas F. Meyer \\ Max-Planck-Institut für Biologie, Abteilung Infektionsbiologie, Spemannstraße 34, D-72076 Tübingen, Germany
}

Received 18 September 1996; accepted 19 September 1996

\begin{abstract}
The pathogenic Neisseria have exploited the processes of horizontal DNA transfer and genetic recombination as mechanisms for the generation of extensive protein variation and modulation of gene expression. Localized recombinations have been well documented in members of multigene families as have alterations in short repetitive sequences. Here we report an analysis of the chromosomal structure of a defined lineage of Neisseria gonorrhoeae strain MS11 pilin variants. This study reveals the occurrence of large rearrangements, including the amplification of a $26 \mathrm{~kb}$ region and an inversion involving more than a third of the chromosome. Additionally, a restriction site polymorphism that correlates with pilin expression has been observed. These findings highlight the flexibility of the gonococcal genome.
\end{abstract}

Keywords: Neisseria; Chromosome; Rearrangement; Inversion

\section{Introduction}

Neisseria gonorrhoeae, the Gram-negative diplococcus causing gonorrhoea in humans, is well-known for its ability to undergo genetic recombinations, leading to exceptional diversity in the expression of cell-surface molecules $[1,2]$. The gonococci are naturally competent for DNA uptake [3], which may serve as a means for the exchange of genetic information between cells. Rearrangements involving members of multi-gene families result in new combinations of variable sequences within these loci, enabling a population to produce a large repertoire of variant proteins that are not only antigenically and immunologically distinct, but may also have altered

\footnotetext{
* Corresponding author. Present address: IMMUNO AG, Uferstraße 15, A-2304 Orth an der Donau, Austria. Tel.: +43 (2212) 2701 350; Fax: +43 (2212) 2716.
}

functional properties. Transformation-mediated recombinations can also lead to changes in singlecopy genes $[4,5]$. In addition to the larger regions involved in recombinations, localized genetic changes modulate expression of specific proteins: short repetitive regions are subject to alterations in the number of repeats, allowing a fine-tuning of gene expression [1].

Despite its relatively small size (approx. $2.3 \mathrm{Mb}$ $[6,7])$, the gonococcal genome contains several multi-copy gene families. In some cases, the sequence homology extends well beyond the coding regions, perhaps reflecting the duplication of a larger region. A short repetitive sequence and a multi-copy transposon-like element have also been identified [8]. Other duplications have been observed to occur in vitro; initial attempts to mutagenize the pilA locus led to heterodiploidy of the region [9].

Physical and genetic maps have been obtained for 


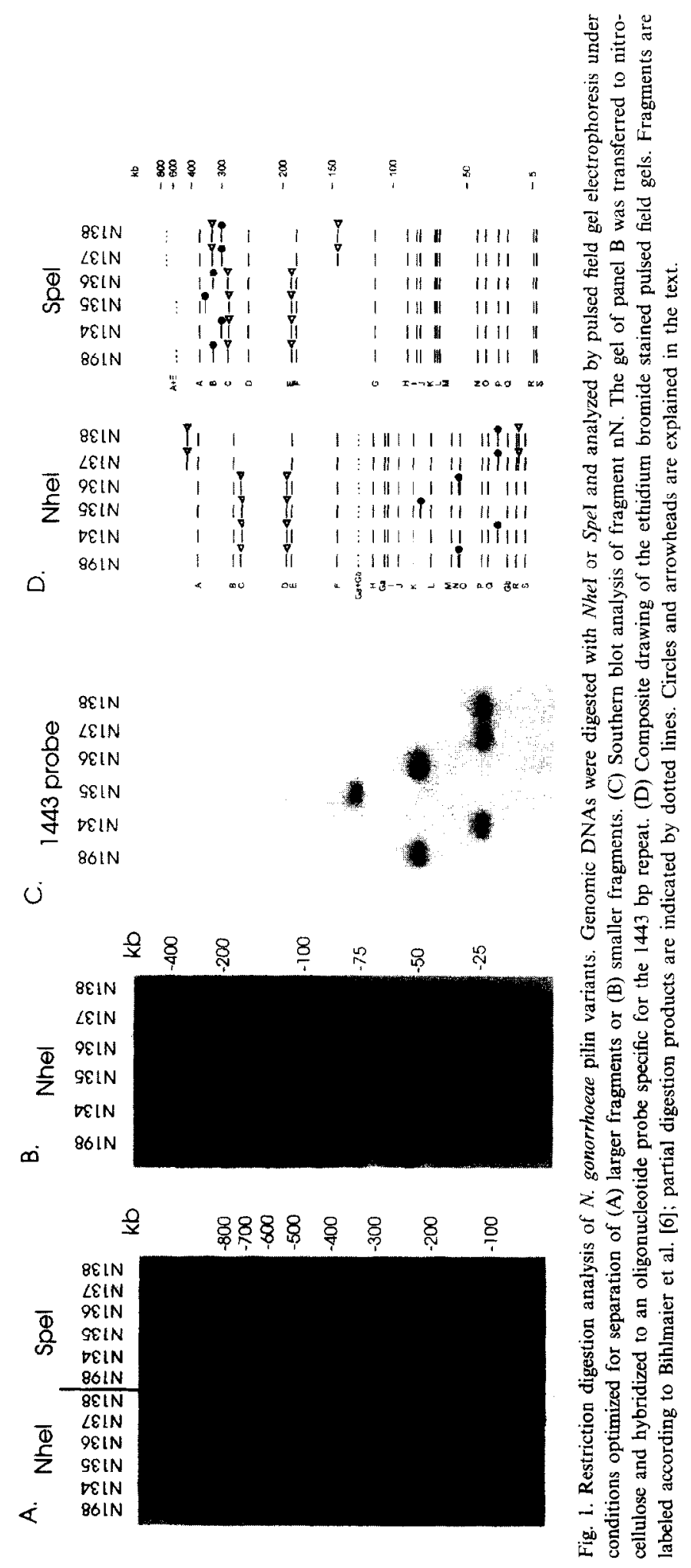



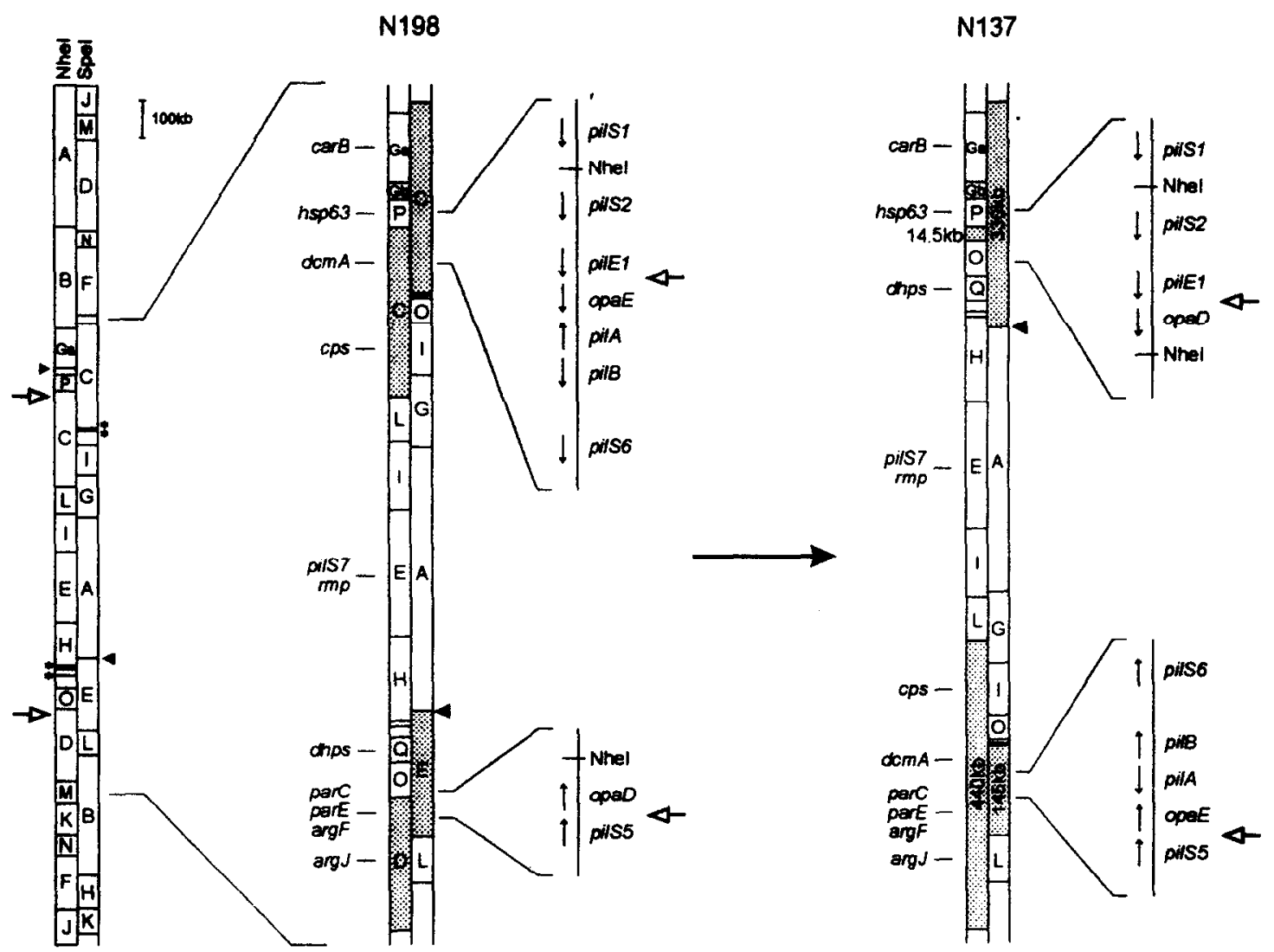

Fig. 2. Chromosomal inversion in variant N137. The physical map of variant N198 [6] is compared to that of N137. Arrows define the limits of the inversion; restriction fragments involved are indicated by shading. Arrowheads indicate semi-resistant restriction sites; restriction fragments whose locations remain tentative are marked with asterisks.

two gonococcal strains, FA1090 [7] and MS11-N198 [6]. The maps are similar, but do show, in addition to restriction site polymorphisms, significant differences in the locations of certain genes. Additionally, the MS11-N198 chromosome (over $2.3 \mathrm{Mb}$ ) is slightly larger than that of FA1090 (approx. 2.2 $\mathrm{Mb})$. Differences have also been observed within strains. The original MS11 isolate (MS11-A) contains two pilE loci [10]; this arrangement is unstable in vitro, one of the loci being usually deleted upon passage. Other differences are seen in the number of opa loci present in MS11 variants [11,6]. Furthermore, a comparison of the gonococcal genetic maps with those of $N$. meningitidis strains B1940 [12] and Z2491 [13] reveals a series of complex rearrangements between the two species.

These observations suggest $N$. gonorrhoeae has a relatively flexible chromosome. We have used a defined lineage of pilin variants to investigate the stability of the gonococcal genome in vitro. Restriction analyses of Nhel, SpeI and double-digested chromosomal DNA revealed several changes in banding pattern among the different variants. These changes reflect a region of expansion/contraction, a large chromosomal inversion and a restriction site polymorphism.

\section{Materials and methods}

\subsection{Bacterial strains}

N198 [6] is a $\operatorname{rec} A$ derivative of $N$. gonorrhoeae strain MS11-A, deposited in the American Type Cul- 
ture Collection (ATCC 49759). The lineage of pilin variants, N134, N135, N136, N137 and N138, was derived from MS11-A and has been described by Haas et al. [14].

\subsection{Molecular biological techniques}

Preparation of genomic DNA, restriction digestion, pulse field gel electrophoresis and Southern hybridizations were performed according to Bihlmaier et al. [6].

\section{Results}

\subsection{MSI1 pilin variants have different restriction patterns}

NheI and SpeI, which had been employed in the construction of the MS11-N198 chromosomal map [6], were used to analyze a series of gonococcal pilin variants descending from MS11-A [14]. Initial experiments revealed numerous alterations in the restriction patterns (Fig. 1), three of which were readily interpretable. In N198, both the $\mathrm{nC}$ and $\mathrm{sC}$ bands and the $\mathrm{nJ}$ and $\mathrm{sK}$ bands are slightly larger than their counterparts in the other variants. The $\mathrm{nC}$ and $\mathrm{sC}$ size difference of $\sim 0.4 \mathrm{~kb}$ is due to the presence of pilE2, a locus found in the parental MS11-A and in the isogenic recA derivative, N198, but de- leted in N134 and therefore not present in the subsequent variants [15]. The slight difference in size (800 bp) of $\mathrm{nJ}$ and $\mathrm{sK}$ results from the $\mathrm{Cl9a}$ recA mutation in $\mathrm{N} 198$; the other variants contain the wild-type recA gene. Likewise, the slight increase in size of $\mathrm{nC}$ and $\mathrm{sC}$ in variant $\mathrm{N} 136$ results from the $\sim 0.4 \mathrm{~kb}$ increase in the pile locus due to the overlength L-pilin gene in this variant [16]. Other changes can be seen with $\mathrm{nC}, \mathrm{nD}$ and $\mathrm{nN}$ and $\mathrm{sB}, \mathrm{sC}, \mathrm{sE}$ and the $s A+s E$ partial digestion product. These changes are more complex, and were analyzed by Southern hybridizations, as described below.

\subsection{Fragment $n N / s B$ undergoes discrete size variations}

A $55 \mathrm{~kb}$ fragment, $\mathrm{nN}$, is present in NheI digests of N198 and N136, but not in the other variants (Fig. 1D, circles). Instead, novel fragments appear; in N134, N137 and N138 a band of $29 \mathrm{~kb}$ can be seen, while an $81 \mathrm{~kb}$ band is found in N135. Both the aro $A$ locus and the 1443 bp repeat have been mapped to fragment $\mathrm{nN}$ in N198 [6]. Hybridization with an oligonucleotide probe specific for the 1443 bp repeat (Fig. 1C) and with the cloned aroA gene (data not shown) demonstrated that the $29 \mathrm{~kb}$ fragment of N134, N137 and N138 and the $81 \mathrm{~kb}$ fragment of $\mathrm{N} 135$ correspond to the $55 \mathrm{~kb} \mathrm{nN}$ fragment of N198 and N136. In each case, the fragment expands or contracts in increments of $26 \mathrm{~kb}$. The $\mathrm{nN}$

Table 1

Southern hybridization analysis of varikbants N198 and N137

\begin{tabular}{|c|c|c|c|c|}
\hline \multirow[t]{2}{*}{ Locus } & \multicolumn{2}{|l|}{ NheI } & \multicolumn{2}{|l|}{ SpeI } \\
\hline & N198 & $\mathrm{N} 137$ & N198 & N137 \\
\hline $\operatorname{car} B$ & $n G a, n G a+n G b$ & nGa, nGa+nGb & $\mathrm{s} C$ & $330 \mathrm{~kb}, \mathrm{sA}+330 \mathrm{~kb}$ \\
\hline hsp63 & $\mathrm{nP}$ & $\mathrm{nP}$ & $\mathrm{sC}$ & $330 \mathrm{~kb}, \mathrm{sA}+330 \mathrm{~kb}$ \\
\hline pilEI & $\mathrm{nC}$ & $14.5 \mathrm{~kb}$ & $\mathrm{sC}$ & $330 \mathrm{~kb}, \mathrm{sA}+330 \mathrm{~kb}$ \\
\hline pil $A, B$ & $\mathrm{nC}$ & $440 \mathrm{~kb}$ & $\mathrm{sC}$ & $145 \mathrm{~kb}$ \\
\hline$d c m A$ & $\mathrm{nC}$ & $440 \mathrm{~kb}$ & $\mathrm{sC}$ & $145 \mathrm{~kb}$ \\
\hline$c p s$ & $\mathrm{nC}$ & $440 \mathrm{~kb}$ & sl & sl \\
\hline$r m p$ & $\mathrm{nE}$ & $\mathrm{nE}$ & $\mathrm{sA}, \mathrm{sA}+\mathrm{sE}$ & $\mathrm{sA}, \mathrm{sA}+330 \mathrm{~kb}$ \\
\hline dhps & $\mathrm{nQ}$ & $\mathrm{nQ}$ & $s E, s A+s E$ & $330 \mathrm{~kb}, \mathrm{sA}+330 \mathrm{~kb}$ \\
\hline$O p a D$ & $\mathrm{nD}$ & $14.5 \mathrm{~kb}$ & $\mathrm{~s} E, \mathrm{sA}+\mathrm{sE}$ & $330 \mathrm{~kb}, \mathrm{~s} \Lambda+330 \mathrm{~kb}$ \\
\hline pils5 & $\mathrm{nD}$ & $440 \mathrm{~kb}$ & $s E, s A+s E$ & $145 \mathrm{~kb}$ \\
\hline $\operatorname{par} C, E$ & $\mathrm{nD}$ & $440 \mathrm{~kb}$ & $\mathrm{sE}, \mathrm{sA}+\mathrm{sE}$ & $145 \mathrm{~kb}$ \\
\hline $\arg F$ & $\mathrm{nD}$ & $440 \mathrm{~kb}$ & $\mathrm{sE}, \mathrm{sA}+\mathrm{sE}$ & $145 \mathrm{~kb}$ \\
\hline $\arg J$ & $\mathrm{nD}$ & $440 \mathrm{~kb}$ & $s \mathrm{~L}$ & $\mathrm{sL}$ \\
\hline
\end{tabular}

Nhel and Spel fragments hybridizing to the particular probe used are indicated for variants N198 and N137. 
fragment is located within the SpeI fragment sB; corresponding size alterations of $26 \mathrm{~kb}$ increments are evident in this fragment (Fig. 1D, circles).

The nature of the size alterations in fragment $\mathrm{nN}$ is unknown, but the fact that these changes occur in discrete $26 \mathrm{~kb}$ increments suggests that a region of this size is able to undergo amplification and condensation. The most simple explanation is that a 26 $\mathrm{kb}$ element is present in a single copy in variants N134, N137 and N138, in duplicate in variants $\mathrm{N} 198$ and N136, and in triplicate in variant N135. As the size of $\mathrm{nN}$ in variants N134, N137 and N138 is only $29 \mathrm{~kb}$, the amplifiable region must encompass nearly the entirety of this fragment; the flanking fragments, $\mathrm{nF}$ and $\mathrm{nK}$, do not undergo size alterations. It is of interest to note that the gonococcal $1443 \mathrm{bp}$ repeat, a transposon-like element of unknown function [8], maps to fragment $\mathrm{nN}$, and thus it is tempting to speculate that this element may be involved in the size alterations.

\subsection{Chromosomal inversion in variant $N 137$}

Comparison of the restriction patterns of the six variants revealed a major alteration occurred between variants N136 and N137 (Fig. 1D, arrowheads). In NheI digests, fragments $\mathrm{nC}(261 \mathrm{~kb})$ and $\mathrm{nD}(196 \mathrm{~kb})$ were lost, while two new bands of approx. 440 and $14.5 \mathrm{~kb}$ could be observed. Because of the semi-resistant cleavage site between fragments $\mathrm{SA}$ and sE [6], the SpeI pattern is more complex. However, it is evident that neither fragment $\mathrm{sC}(288 \mathrm{~kb})$ nor $\mathrm{sE}(191 \mathrm{~kb})$ is present in N137, where novel bands of 330 and $145 \mathrm{~kb}$ appear. In addition, the $\mathrm{sA}+\mathrm{sE}$ partial digestion product $(565 \mathrm{~kb})$, seen in $\mathrm{N} 198$ and $\mathrm{N} 135$, but not in $\mathrm{N} 134$ or N136, is replaced with a larger fragment $(705 \mathrm{~kb})$ in $\mathrm{N} 137$; the complete digestion product, sA $(374 \mathrm{~kb})$, does not change in size. The altered restriction pattern was inherited in the daughter variant, N138.

The conserved size changes of the fragments involved ( $\mathrm{nC} / \mathrm{sC}$ and $\mathrm{nD} / \mathrm{sE}$ ) suggested an inversion occurred involving these regions (Fig. 2). From size calculations, it could be deduced that the crossover occurred in $\mathrm{nC}$, close to $\mathrm{nP}$, and in $\mathrm{nD}$, close to $\mathrm{nO}$. Inversion involving these regions would result in a large NheI fragment, encompassing most of $\mathrm{nC}$ and $\mathrm{nD}$, and a small NheI fragment, containing the re- mainder. Rearrangement in these two regions would also lead to changes in the size of both $\mathrm{sC}$ and $\mathrm{sE}$, which in turn alters the size of the partial digestion product, sA+sE. Novel SpeI fragments of 145 and $330 \mathrm{~kb}$ are consistent with this interpretation, as is the $705 \mathrm{~kb}$ size of the partial digestion product [sA $(374 \mathrm{~kb})+330 \mathrm{~kb}$. Furthermore, in two-dimensional reciprocal gels of the $\mathrm{N} 137$ chromosome, it could be demonstrated that NheI fragments $\mathrm{nE}, \mathrm{nGa}+\mathrm{nGb}$, $\mathrm{nH}, \mathrm{nO}$ and $\mathrm{nP}$ are contained within the large SpeI partial digestion product, and that SpeI fragments sI, $\mathrm{sL}, \mathrm{sO}$ and the $145 \mathrm{~kb}$ fragment are contained within the $440 \mathrm{~kb}$ NheI fragment (data not shown; in these experiments, fragments smaller than $36 \mathrm{~kb}$ were beyond the limits of resolution).

To further analyze the rearrangement, Southern hybridizations were performed with $\mathrm{N} 198$ and $\mathrm{N} 137$, using probes specific for the fragments involved or for flanking fragments. These results are summarized in Table 1, and are consistent with a large inversion having occurred, with the cross-over located within $14.5 \mathrm{~kb}$ from the $\mathrm{nP}-\mathrm{nC}$ and the $\mathrm{nO}$ $\mathrm{nD}$ sites, within $\mathrm{nC} / \mathrm{sC}$ and $\mathrm{nD} / \mathrm{sE}$. Thus pilA, pilB and $\operatorname{dcm} A$, found in the $\mathrm{nC} / \mathrm{sC}$ fragment in $\mathrm{N} 198$ and pilS5, parC, parE and $\arg F$, found in the $\mathrm{nD} / \mathrm{sE}$ fragment in N198 all map to the $440 \mathrm{~kb}$ NheI fragment and the $145 \mathrm{~kb}$ SpeI fragment in N137.

Both of the regions involved in the inversion contain pil and opa loci [6]; in $\mathrm{N} 136$, the $\mathrm{nC} / \mathrm{sC}$ fragment contains the closely linked pilEl and opaE, as well as pilS2 and pilS6, while the linked pilS5 and $o p a D$ [17] are located in the $\mathrm{nD} / \mathrm{sE}$ fragment. To investigate the possibility of recombination involving the pil-opa loci, hybridizations were performed using pil- and opa-specific oligonucleotide probes (Table 1). In $\mathrm{N} 198$, the pilE probe hybridized to $\mathrm{nC}$ and the pilS5 and opaD probes hybridized to $\mathrm{nD}$. In contrast, in N137, opaD and pilE have identical hybridization patterns, mapping to the $14.5 \mathrm{~kb}$ NheI fragment, while the pilS5 probe hybridized to the $440 \mathrm{~kb}$ NheI fragment. As opaE does not contain unique sequences [11], no probe was available to examine definitively this locus. Nevertheless, the data suggest the inversion breakpoints are located within pilEl$o p a E$ and pilS5-opaD, leading to a pilE1-opaD linkage and a pilS5-opaE linkage (Fig. 2). The cross-over must have occurred upstream of the opa semi-variable domain, as the opaD probe hybridizes in this 
region. Likewise, the extent of homology between pilE1 and pilS5, starting at codon 44 of the mature protein, defines the $5^{\prime}$ limit for recombination. The distance between these regions in pilEl and opaE is less than $1 \mathrm{~kb}$.

Localized RecA-dependent recombination events involving members of the pil and opu multi-gene families have been well documented in $N$. gonorrhoeae. However, the large chromosomal inversion occurring in variant $\mathrm{N} 137$ between the pilE1, opaE and pilS5, opaD loci is the first known example of a major chromosomal rearrangement in this species. One consequence of the inversion is the uncoupling of the regulatory genes, pilA and pilB, from the expressed pilE locus. That variant $\mathrm{N} 137$ and its progeny N138 exhibit no detectable alterations in pilin expression or degree of piliation (data not shown) demonstrates that physical coupling of the regulatory genes to pilE is not essential.

\subsection{SpeI polymorphism}

A semi-resistant SpeI cleavage site had been previously identified between fragments $\mathrm{SA}$ and $\mathrm{sE}$ [6]. In Fig. 1, it can be seen that the susceptibility of this site to digestion varies in the different variants. In N134 and N136, virtually complete digestion was obtained at this site. In contrast, in N198, N135, $\mathrm{N} 137$ and N138, digestion was very poor, and the large partial digestion product (Fig. 1D, dotted lines) remained refractory to digestion. In N137 and N138, this band is larger $(705 \mathrm{~kb})$ than that seen in N198 and N135 $(565 \mathrm{~kb})$, due to the inversion involving fragment $\mathrm{sE}$ (see above). Southern hybridizations using probes specific for this region have confirmed that the $705 \mathrm{~kb}$ band derives from a partial digestion of fragments sA $(374 \mathrm{~kb})$ and the $330 \mathrm{~kb} \mathrm{SpeI} \mathrm{frag-}$ ment resulting from the inversion (Table 1). Resistance of the sA-sE site to digestion correlates with pilus production in these six variants, however, examination of additional pilin variants and mutants (data not shown) indicates that, although strong, the correlation is not absolute.

The fact that this site digests well in some variants but poorly in others suggests that digestion may be related to gene expression in this region. The physical basis for the resistance to digestion in certain variants is unknown. Although SpeI has no known site preference or sensitivity to methylation, these possibilities cannot be ruled out at present. Another possibility could be a localized rearrangement involving the SpeI site; the site may be present in one configuration but absent in the other. In this case, the degree of digestion in a given DNA preparation might reflect the proportion of the bacterial population in the configuration amenable to digestion. Any alterations in this region must be conservative or below the limits of detection (approx. $500 \mathrm{bp}$ ), as the NheI fragment, $\mathrm{nH}$, which spans the semi-resistant SpeI site, does not show detectable alterations in size.

\subsection{Chromosomal flexibility}

Our analysis of a defined lineage of $N$. gonorrhoeae pilin variants indicates this organism possesses a highly flexible genome. Recombination events among members of the multi-gene pil and opa families have been well-documented $[18,19]$ and horizontal gene transfer is proposed to occur in vivo $[4,5]$. Localized genetic changes involving alterations in the number of short repeated sequences have been observed in several genes [20-24]. We now demonstrate the occurrence of larger rearrangements, including chromosomal inversion and amplification of a $26 \mathrm{~kb}$ unit. Furthermore, we identify an SpeI restriction site polymorphism that shows correlation with pilus production.

\section{References}

[1] Meyer, T.F., Pohlner, J. and Van Putten, J.P.M. (1994) Biology of the pathogenic Neisseria. Curr. Top. Microbiol. 192 , 283-309.

[2] Seifert, H.S. (1996) Questions about gonococcal pilus phase and antigenic variation. Mol. Microbiol. 21, 433-440.

[3] Sparling, P.F. (1966) Genetic transformation of Neisseria gonorrhoeae to streptomycin resistance. J. Bacteriol. 92, 1364 1370.

[4] Halter, R., Pohlner, J. and Meyer, T.F. (1989) Mosaic-like organization of $\lg$ A protease genes in Neisseria gonorrhoeae generated by horizontal genetic exchange in vivo. EMBO J. 8 , 2737 -2744

[5] Spratt, B.G. (1988) Hybrid penicillin-binding proteins in penicillin-resistant strains of Neisseria gonorrhoeae. Nature 332, 173-176.

[6] Bihlmaier, A., Römling, U., Meyer, T.F., Tümmler, B. and 
Gibbs, C.P. (1991) Physical and genetic map of the Neisseria gonorrhoeae strain MS11-N198 chromosome. Mol. Microbiol. 5, 2529-2539.

[7] Dempsey, J.F., Litaker, W., Madhure, A., Snodgrass, T. and Cannon, J.G. (1991) Physical map of the chromosome of Neisseria gonorrhoeae FA1090 with locations of genetic markers, including opa and pil genes. J. Bacteriol. 173, 5476-5486.

[8] Correia, F.F., Inouye, S. and Inouye, M. (1988) A family of small repeated elements with some transposon-like properties in the genome of Neisseria gonorrhoeae. J. Biol. Chem. 263, 12194-12198.

[9] Taha, M.K., So, M., Seifert, H.S., Billyard, E. and Marchal, C. (1988) Pilin expression in Neisseria gonorrhoeae is under both positive and negative transcriptional control. EMBO J. 7, 4367-4378.

[10] Meyer, T.F., Billyard, E., Haas, R., Storzbach, S. and So, M. (1984) Pilus gene of Neisseria gonorrhoeae: chromosomal organization and DNA sequence. Proc Natl. Acad. Sci. USA 81, $6110-6114$.

[11] Bhat, K.S., Gibbs, C.P., Barrera, O., Morrison, S.G., Jähnig, F., Stern, A., Kupsch, E.-M., Meyer, T.F. and Swanson, J. (1991) The opacity proteins of Neisseria gonorrhoeae strain MS11 are encoded by a family of 11 complete genes. Mol. Microbiol. 5, 1889-1901.

[12] Gäher, M., Einsiedler, K., Crass, T. and Bautsch, W. (1992) A physical and genetic map of Neisseria meningitis B1940. Mol. Microbiol. 19, 249-259.

[13] Dempsey, J.A.F., Wallace, A.B. and Cannon, J.G. (1995) The physical map of the chromosome of a serogroup A strain of Neisseria meningitidis shows complex rearrangements relative to the chromosomes of the two mapped strains of the closely related species $N$, gonorrhoeae. J. Bacteriol. 177, 6390-6400.

[14] Haas, R., Schwarz, H. and Meyer, T.F. (1987) Release of soluble pilin antigen coupled with gene conversion in Neisseria gonorrhoeae. Proc. Natl. Acad. Sci. USA 84, 9079-9083.

[15] Segal, E., Billyard, E., So, M., Storzbach, S. and Meyer, T.F.
(1985) Role of chromosomal rearrangement in $N$. gonorrhoeae pilus phase variation. Cell 40, 293-300.

[16] Manning, P., Kaufmann, A., Roll, U., Pohlner, J., Mcyer, T.F. and Haas, R. (1991) L-Pilin variants of Neisseria gonorrhoeae MS11. Mol. Microbiol. 5, 917-926.

[17] Haas, R., Veit, S. and Meyer, T.F. (1992) Silent pilin genes of Neisseria gonorrhoeae MS11 and occurrence of related hypervariant sequences among other gonococcal isolates. Mol. Microbiol. 6, 197-208.

[18] Gibbs, C.P., Reimann, B.Y., Schultz, E., Kaufmann, A., Haas, R. and Meyer, T.F. (1989) Reassortment of pilin genes in Neisseria gonorrhoeae occurs by two distinct mechanisms. Nature 338, 651-652.

[19] Seifert, H.S., Ajioka, R.S., Marchal, C., Sparling, P.F. and So, M. (1988) DNA transformation leads to pilin antigenic variation in Neisseria gonorrhoeae. Nature 336, 392-395.

[20] Stern, A., Brown, M., Nickel, P. and Meyer, T.F. (1986) Opacity genes in Neisseria gonorrhoeae: control of phase and antigenic variation. Cell 47, 61-71.

[21] Belland, R.J., Morrison, S.G., Van der Ley, P. and Swanson, J. (1989) Expression and phase variation of gonococcal P.II genes in Escherichia coli involves ribosomal frameshifting and slipped-strand mispairing. Mol. Microbiol. 3, 777-786.

[22] Connell, T.D., Black, W.J., Kawula, T.H., Barritt, D.S., Dempsey, J.A., Kverneland, J.R.K., Stephenson, A., Schepart, B.S., Murphy, G.L. and Cannon, J.G. (1988) Recombination among protein II genes of Neisseria gonorrhoeae generates new coding sequences and increases structural variability in the protein II family. Mol. Microbiol. 2, 227-236.

[23] Jonsson, A.B., Nyberg, G. and Normark, S. (1991) Phase variation of gonococcal pili by frameshift mutation in pilC, a novel gene for pilus assembly. EMBO J. 10, 477-488.

[24] Gotschlich, E.C. (1994) Genetic locus for the biosynthesis of the variable portion of Neisseria gonorrhoeae lipooligosaccharide. J. Exp. Med. 180, 2181-2190. 